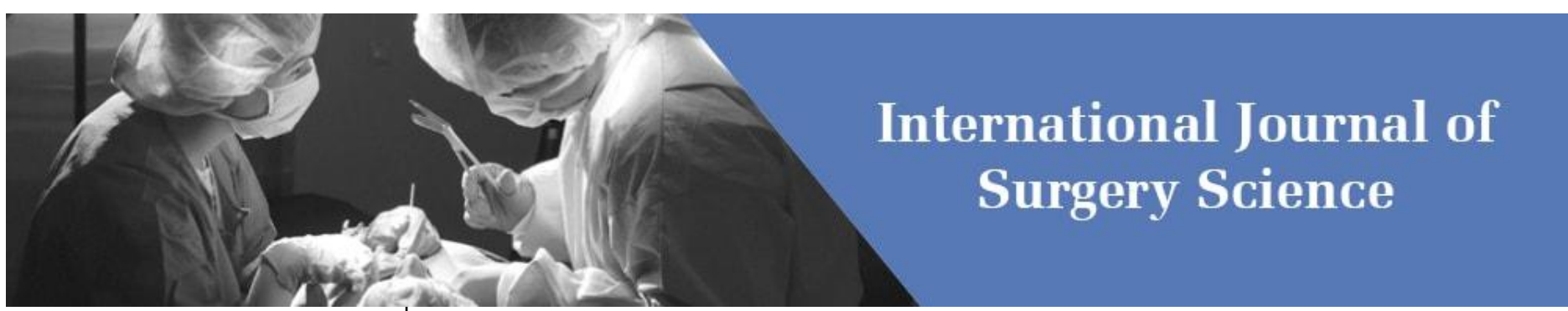

E-ISSN: 2616-3470

P-ISSN: 2616-3462

(c) Surgery Science

www.surgeryscience.com

2020; 4(2): 641-645

Received: 28-02-2020

Accepted: 29-03-2020

Dr. Goutham Kompally

Assistant Professor, Department of

General Surgery, Kamineni

Institute of Medical Sciences,

Narkatpally, Nalgonda District,

Telanagana, India.

Dr. K Suresh Kumar

Associate Professor, Department of

General Surgery, Kamineni

Institute of Medical Sciences,

Narkatpally, Nalgonda District,

Telanagana, India.

Corresponding Author:

Dr. K Suresh Kumar

Associate Professor, Department of

General Surgery, Kamineni

Institute of Medical Sciences,

Narkatpally, Nalgonda District,

Telanagana, India.

\section{A prospective study on post operative complications of thyroid surgery}

\section{Dr. Goutham Kompally and Dr. K Suresh Kumar}

DOI: https://doi.org/10.33545/surgery.2020.v4.i2g.477

\section{Abstract}

Background: The various postoperative complications of thyroid surgery have long been known to surgeons embarking on the surgical treatment of goitre. These complications may be severe enough to jeopardise the life of the patient or to create a physical or physiological incapacity which will limit his normal activities. Because of the severity of the complications it becomes necessary to reduce the incidence of these complications to an absolute minimum in this age of modern surgery.

Aims \& Objectives: Aim of this study is to study the preoperative factors which influence complication rates, complication rates associated with the type of thyroid surgery, type of complications, period of onset of complications, hospital stay of patient with different complications, mode of management of each complications.

Materials and Methods: The present study of "Postoperative complications of Thyroid Surgery "has been made over a period of 18 months from January 2017 to July 2019.The study was made in Kamineni institute of Medical Sciences Narkatpally. Prospective analysis of 60 goitres undergoing surgery were taken for the study. These cases were studied in detail clinically and recorded as per the proforma attached. Results: Prospective analysis of 60 goitres undergoing surgery showed the incidence of thyroid diseases is more common in females than in males. The peak age group in which patients presented to the hospital was in $3^{\text {rd }}$ decade. The commonest clinical diagnosis in patients with goitre was Multinodular Goitre in Euthyroid status. The commonest histological diagnosis in those specimens sent for Histopathological examination was Nodular Colloid Goitre. The most common surgery performed in goitre cases was Subtotal thyroidectomy. Wound infection was the most common post- operative complication.

Conclusion: In this study the mortality was zero and morbidity was low. Thyroid surgery is safe and can be performed with minimum morbidity and mortality for a wide range of diseases of thyroid, if it is done gently with meticulous attention to achieve adequate hemostasis with identification and preservation of structural details.

Keywords: Thyroidectomy, Hypoparathyroidism, Hypothyroidism, Hemorrhage, Recurrent Laryngeal Nerve Palsy.

\section{Introduction}

Thyroid surgery is one of the most commonly performed surgery for benign and malignant conditions of the thyroid gland worldwide.

The thyroid gland is closely related to many vital structures and hence poses a unique challenge to the surgeon

The first accounts of thyroid surgery for the treatment of goitres were given by Roger Frugardi in 1170. In response to failure of medical treatment, two setons were inserted at right angles into the goitre and tightened twice daily until the goitre separated. The open wound was treated with caustic powder and left to heal.

However, thyroid surgery continued to be hazardous with prohibitive mortality rates $(>40 \%)$ until the latter half of the nineteenth century, when advances in general anaesthesia, antisepsis, and hemostasis enabled surgeons to perform thyroid surgery with significantly reduced mortality and morbidity rates.

The most notable thyroid surgeons were Emil Theodor Kocher (1841-1917) and C.A. Theodor Billroth (1829-1894), who performed thousands of operations with increasingly successful results.

However, as more patients survived thyroid operations, new problems and issues became apparent. 
Some of the complications are life threatening, hence an attempt is made to study the various complications of thyroid surgery.

\section{Aims \& Objectives}

1. Preoperative factors which influence complication rates

2. Complication rates associated with the type of thyroid surgery

3. Type of complications

4. Period of onset of complications(time interval between surgery and complications)

5. Hospital stay of patient with different complications of thyroid surgery.

6. Mode of management of each complication

\section{Materials and Methods}

The present study of "Postoperative complications of Thyroid Surgery "has been made over a period of 18 months from January 2017 to July 2019.The study was made in Hospital attached to Kamineni Institute of Medical Sciences.

Prospective analysis of 60 goitres undergoing surgery were taken for the study. These cases were studied in detail clinically and recorded as per the proforma attached.

\section{Methods of collecting data \\ Sample size: Minimum of 50 cases}

\section{Sampling method: Simple random sampling}

Inclusion criteria: All patients who are posted for thyroid surgery in Kamineni Institute of Medical Sciences.

Exclusion criteria: Patients with previous thyroid surgery and anaesthetic complications.

\section{Methods}

The details of the patient were recorded according to the proforma. The chief complaints were recorded in a chronological order and the history asked in detail along with past history familial history personal history.

The mode of onset of Goitre, its progression, whether associated with pain, sudden enlargement of the swelling were asked in detail. The cosmetic effects of the swelling and its impact on the routine life were recorded.

In the history special preference was given to the symptoms suggestive of hyper/hypo thyroidism, symptoms suggestive of pressure effects like dysphagia, stridor, dysphonia. The medication history was also taken and history of previous irradiation was also taken.

The patients were then examined in detail.

The General Physical Examination was done with attention to anaemia, icterus, clubbing, lymphadenopathy, edema, height, weight, BMI, facies etc.

The Local Examination was divided into four parts; inspection, palpation, percussion and auscultation.

On inspection the site, size, shape, surface, extent, borders, skin over and around the goitre were noted. Movement upwards on deglution was given special importance.

On palpation, the tenderness and local rise of temperature (if any) were noted. The inspector findings were confirmed. The consistency of the goitre along with nodules (if any) were noted. Thyroid fixity was checked. The tracheal position was confirmed. The carotid pulsations were checked for their position. Cervical lymph node areas were palpated.

On percussing the manubrium sternum retrosternal extension or mediastinal lymphadenopathy was noted.

Auscultation of the thyroid gland especially at the superior poles for bruit was done. The various eye signs of thyrotoxicity was checked in selected patients.

The Systemic Examination was done where the cardiovascular, nervous (including the spine), respiratory and the abdomen systems were examined in detail with special attention to any signs of metastasis.

After examination the patient was subjected to relevant investigations. Routine investigations like $\mathrm{Hb} \%$, bleeding time, clotting time, RBS, Urea, Creatinine, Urine Routine, Chest Xray, Electrocardiogram were done.

Plain X-ray of the neck in antero-posterior views and lateral views were taken to look for tracheal deviation or compression. Chest X-ray for retro-sternal extension was done. Thyroid Profile $\left(\mathrm{T}_{3}, \mathrm{~T}_{4}, \mathrm{TSH}\right)$ were done to know about the hormonal status. FNAC was done in all cases to establish the histological diagnosis. Ultrasound neck was done in selected cases only.

Indirect Laryngoscopy was done routinely in all cases to look for vocal cord status.

The preoperative treatment consisted of correction of co-morbid conditions (if any) and maintenance of euthyroid status.

In this study all patients were non-diabetic.

Depending on the diagnosis appropriate surgery was done.

During surgery utmost precaution was taken to preserve the nerves and the parathyroid glands. Attention was paid to meticulous hemostasis and whether the trachea was softened(in long standing goitres).

Drains were kept in all cases.

Movements of the vocal cords were noted at the end of operation. The operated specimen was sent for histopathological examination for confirmation of the clinical diagnosis in every case. Postoperatively patients were observed in the recovery room, for reactionary hemorrhage and respiratory distress. Patients were examined for signs of hypocalcemia and relevant investigations like serum calcium were ordered in cases of suspected hypocalcemia.

All patients were treated with antibiotics postoperatively. Suction drains were placed in all cases and usually removed after 48 hours.

Routinely sutures were removed in all cases by $6^{\text {th }}$ or $7^{\text {th }}$ postoperative day. Patients were discharged on the same day. Regular follow up was done in all cases.

All patients were followed up regularly to look for signs of hyper/hypo thyroidism. In those patients who had evidence of voice change or hoarseness, Indirect Laryngoscopy was done. Appropriate investigations like thyroid profile, serum calcium were done during the follow up period as required.

\section{Results}

Table 1: Age Distribution

\begin{tabular}{|c|c|c|c|c|}
\hline Age(in years) & Female & Male & Total & Percentage \\
\hline $10-19$ & 2 & 1 & 3 & 5 \\
\hline $20-29$ & 15 & 3 & 18 & 30 \\
\hline $30-39$ & 10 & 2 & 12 & 20 \\
\hline $40-49$ & 9 & 2 & 11 & 18.33 \\
\hline $50-59$ & 5 & 0 & 5 & 8.33 \\
\hline $60-69$ & 7 & 3 & 10 & 16.66 \\
\hline $70-79$ & 0 & 1 & 1 & 1.66 \\
\hline Total & 48 & 12 & 60 & 100 \\
\hline
\end{tabular}

Among the 60 patients who underwent thyroid surgery, the youngest patient was 18 years of age and the oldest was 71 years 
of age. The peak age group of individuals undergoing surgery was in the $3^{\text {rd }}$ decade.

Table 2: Sex Distribution

\begin{tabular}{|c|c|c|}
\hline Sex & Number of cases & Percentage \\
\hline Female & 50 & 83.33 \\
\hline Male & 10 & 16.66 \\
\hline
\end{tabular}

Out of the 60 cases studied, 50 were females and 10 were males with a sex ratio of $\mathrm{F}: \mathrm{M}=7.75: 1$

Table 3: Clinical Diagnosis

\begin{tabular}{|c|c|c|}
\hline Clinical diagnosis & Number of Patients & Percentage \\
\hline Solitary nodular goitre & 15 & 25 \\
\hline Multinodular goitre & 40 & 66.66 \\
\hline Toxic multinodular goitre & 5 & 8.33 \\
\hline Total & 60 & 100 \\
\hline
\end{tabular}

In the present series,most of the goitres were clinically diagnosed as multinodular goitres $(66.6 \%)$.Next most common diagnosis was Solitary nodule goitre $(25 \%)$.

Table 4: Histopathological Diagnosis

\begin{tabular}{|c|c|c|}
\hline Diagnosis & Number of Patients & Percentage \\
\hline Colloid Goitre & 4 & 6.66 \\
\hline Multinodular Goitre & 15 & 25 \\
\hline Nodular Colloid Goitre & 16 & 26.66 \\
\hline Benign neoplasia & 08 & 13.33 \\
\hline Malignant neoplasia & 2 & 3.33 \\
\hline Hashimoto's Thyroiditis & 2 & 3.33 \\
\hline Nodular Hyperplasia & 1 & 1.66 \\
\hline Total & 60 & 100 \\
\hline
\end{tabular}

Out of the 60 cases operated, the histopathological report was as follows: 16 cases were Nodular colloid goitre, 15 cases were Multinodular goitre, 4 cases were Colloid goitre, 8 cases were Benign neoplasia (Follicular adenoma), 2 cases were malignant (Papillary carcinoma), 2 cases were Hashimoto's thyroiditis, 1 case was Nodular hyperplasia.

Table 5: Radiological Findings

\begin{tabular}{|c|c|c|}
\hline X-ray neck & Number of Patients & Percentage \\
\hline Normal Pretracheal soft tissue & 50 & 83.33 \\
\hline Antero-posterior compression & 6 & 10 \\
\hline Tracheal Deviation & 4 & 6.66 \\
\hline Retrosternal Extension & 0 & 0 \\
\hline Calcification & 0 & 0 \\
\hline Total & 60 & 100 \\
\hline
\end{tabular}

Out of 60 cases, the trachea was normal in 50 patients, anteroposterior compression was found in 6 cases and tracheal deviation in 4 patients. The patients who had abnormal findings had longstanding goitres or large goitres.

Table 6: Type of Surgical Procedure

\begin{tabular}{|c|c|c|}
\hline Operative Procedure & Number of Patients & Percentage \\
\hline Sub-total thyroidectomy & 30 & 50 \\
\hline Hemi-thyroidectomy & 10 & 16.66 \\
\hline Total thyroidectomy & 15 & 25 \\
\hline Near total thyroidectomy & 5 & 8.33 \\
\hline Total & 60 & 100 \\
\hline
\end{tabular}

Out of the 60 cases, Subtotal Thyroidectomy was the most common procedure $(50 \%)$, followed by Hemi-thyroidectomy (16.6\%), and Total Thyroidectomy.

Table 7: Complications of Thyroid Surgery

\begin{tabular}{|c|c|c|}
\hline Type of Complication & $\begin{array}{c}\text { Number of } \\
\text { Patients }\end{array}$ & $\begin{array}{c}\text { Percentage of total } \\
\text { cases }\end{array}$ \\
\hline Wound infection & 8 & 13.33 \\
\hline Seroma & 7 & 11.66 \\
\hline Hypoparathyroidism & 3 & 5 \\
\hline Hemorrhage & 1 & 1.66 \\
\hline Transient RLN palsy & 1 & 1.66 \\
\hline Hypothyroidism & 4 & 6.66 \\
\hline Stitch Granuloma & 1 & 1.66 \\
\hline Total number complications & 26 & 43.33 \\
\hline
\end{tabular}

\section{Wound infection}

In this study wound infection was the most common complication. 8 patients had wound infections. The incidence rate of infection was $13.33 \%$.Infection was managed by antibiotics and dressings.

\section{Seroma}

In the present series seroma was found in 7 patients. The incidence rate was $11.6 \%$. It was aspirated in all the cases and appropriate antibiotics were initiated.

\section{Transient Hypoparathyroidism}

In this study Transient Hypoparathyroidism was seen in 3 patients. The incidence rate was $5 \%$. Calcium supplements and vitamin-D was administered and the patients recovered.

\section{Hemorrhage}

In the present series, hemorrhage was seen in only 1 patient. It was observed in the operating room itself when the patient was about to be shifted to the recovery room. The wound was reexplored and hemostasis was achieved.

\section{Transient Recurrent Laryngeal Nerve palsy}

In this study there was only 1 case of Transient Recurrent Laryngeal Nerve palsy. It was treated with corticosteroids.

\section{Hypothyroidism}

In the present series there were 4 patients who developed hypothyroidism. The incidence rate was $6.66 \%$.They were diagnosed during routine follow up. L-Thyroxine was started in all those patients.

\section{Stitch Granuloma}

In this study, there was only 1 case of stitch granuloma. The patient complained of serous discharge from the wound. Regular dressings and antibiotics did not improve the condition. The wound was reexplored and the offending material was removed.

\section{Discussion}

The Thyroid gland is situated in the portion of the neck where it is closely related to numerous important structures. The accidental injury to any one of these vital structures can result in mortality or morbidity. Hence the operating surgeon should take utmost precaution while dissecting these structures.

The complications arising after thyroid surgery can be classified as intra-operative complications and immediate post-operative complications and late post-operative complications.

The successful thyroid surgery requires skill and patience from the surgeon, the anaesthetic team, and all others involved in 
giving holistic healthcare to the patient.

In the present study spanning 18 months (January 2017-July 2019), there were 60 thyroid surgeries performed and 26 complications were documented. The mortality in this series was zero. All the complications were appropriately managed with satisfactory patient outcome.

\section{Wound infection}

\begin{tabular}{|c|c|c|c|}
\hline Studies & Year & Number of cases & Percentage \\
\hline Rosato et al. ${ }^{[1]}$ & 2004 & 14,934 & 0.3 \\
\hline Bergenfelz et al. ${ }^{[3]}$ & 2008 & 3660 & 1.6 \\
\hline Present series & 2019 & 60 & 9.5 \\
\hline
\end{tabular}

The incidence of wound infection in the present series was $13.33 \%$.It is considerably high compared to the other studies.

The wound infection was noted mainly on the $6^{\text {th }}$ or $7^{\text {th }}$ postoperative day. Earliest seen on the $5^{\text {th }}$ postoperative day (2 patients). There was erythema and induration around the suture line, associated with tenderness.

The most fluctuant part of the swelling was drained by removing the overlying sutures. Pus was sent for culture sensitivity and broad spectrum antibiotics were initiated and subsequently changed as per the culture reports. All the infections were superficial, and wound healing was achieved by secondary intention.

The average duration of hospital stay was 17.2 days and the maximum duration was 20 days (in 2 patients).

Seroma

\begin{tabular}{|c|c|c|c|}
\hline Studies & Year & Number of cases & Percentage \\
\hline Suslu et al. . $^{[4]}$ & 2006 & 135 & 1 \\
\hline Present series & 2019 & 60 & 11.6 \\
\hline
\end{tabular}

The incidence of seroma formation in the present series was $11.6 \%$. This is comparable to the Kowalski series.

Seromas was detected around the $8^{\text {th }}$ postoperative day ( 3 out of 6 cases). The earliest seroma was detected on the $7^{\text {th }}$ postoperative day.

The average duration of hospital stay was 16.1 days. The maximum duration of hospital stay was 18 days.

Most of the seromas were seen after subtotal thyroidectomy (5 out of 7 patients), 1 in total thyroidectomy, 1 in hemithyroidectomy.

All the cases which developed seromas had goitres whose one of the dimensions was greater than $6 \mathrm{~cm}$.

All the seromas were aspirated and appropriate antibiotics were started. Healing was seen in all cases.

\section{Hypoparathyroidism}

\begin{tabular}{|c|c|c|c|}
\hline Studies & Year & Number of cases & Percentage \\
\hline Rosato et al. ${ }^{[1 ~ \& 2]}$ & 2004 & 14,934 & 8.3 \\
\hline Erbil.Y et al. ${ }^{[5]}$ & 2007 & 3250 & 6.6 \\
\hline Present series & 2019 & 60 & 5 \\
\hline
\end{tabular}

In the present study, the incidence rate of hypoparathyroidism was $5 \%$ with 4 patients developing temporary hypoparathyroidism.

All the cases of hypoparathyroidism was seen in those who underwent total thyroidectomy. All the cases were temporary hypoparathyroidism because subsequent follow up showed normal serum calcium levels. This was attributed to temporary spasm of the vessels supplying the parathyroid glands and hence the resulting tetany.

\section{Hemorrhage}

\begin{tabular}{|c|c|c|c|}
\hline Studies & Year & Number of cases & Percentage \\
\hline Rosato et al. ${ }^{[1]}$ & 2004 & 14,934 & 1.2 \\
\hline Bergenfelz et al. $^{[3]}$ & 2008 & 3660 & 2.1 \\
\hline Present series & 2019 & 60 & 1.66 \\
\hline
\end{tabular}

In the present series hemorrhage was seen in 1 patient. The incidence rate was $1.66 \%$. This is comparable to the Bhattacharya series.

The patient had underwent total thyroidectomy for multi-nodular goitre. The patient was in the operating room itself and was about to be shifted to the recovery room when it was noted that the drain was high. It was decided to re-explore the wound and bleeding was from the superior pedicle on the left side. The bleeding was controlled and the wound closed once again with a drain.

The post-operative stay in the hospital was 12 days.

Recurrent Laryngeal Nerve Palsy

\begin{tabular}{|c|c|c|c|}
\hline Studies & Year & Number of cases & Percentage \\
\hline Rosato et al. ${ }^{[1]}$ & 2004 & 14,934 & 2 \\
\hline Erbil.Y et al. ${ }^{5]}$ & 2007 & 3250 & 1.8 \\
\hline Present series & 2019 & 60 & 1.66 \\
\hline
\end{tabular}

The incidence of recurrent laryngeal nerve palsy in the present series was $1.66 \%$, with only 1 patient developing that complication. This is comparable to the Bhattacharya series. The patient had underwent Total Thyroidectomy for Multinodular goitre. It was a young male patient.

\section{Hypothyroidism}

\begin{tabular}{|c|c|c|c|}
\hline Study & Year & Number of cases & Percentage \\
\hline Hedley et al. ${ }^{[6]}$ & 1983 & 1170 & 41 \\
\hline Present series & 2019 & 60 & 6.66 \\
\hline
\end{tabular}

The incidence of post-operative hypothyroidism in this study was $6.66 \%$ (4 patients). This is not concordant with the other studies. This is because of the short period of follow up (the maximum period of follow up in this series was 12 months). The average period of follow up being 6.75 months.

\section{Stitch Granuloma}

There was 1 case of stitch granuloma out of the 60 cases operated. The incidence rate being $1.66 \%$.The patient had undergone sub-total thyroidectomy for Hashimoto thyroiditis. The patient complained of serous discharge from the wound site 6 wk after the surgery. The patient was put on antibiotics and anti-inflammatory agents along with regular dressings. But there was no improvement. It was decided to explore the wound. On surgery the offending silk suture was removed. The patient recovered afterwards.

Duration of Hospital stay (post-operative)

\begin{tabular}{|c|c|c|}
\hline & Number of patients & Percentage \\
\hline 5-9 days & 45 & 75 \\
\hline 10-14 days & 5 & 8.33 \\
\hline$>15$ days & 10 & 16.66 \\
\hline
\end{tabular}

Most of the patients were discharged within 5-9 days after surgery. Patients who had complications had their hospital stay extended for upto 18 days (Maximum in 1 patient). 


\section{Follow up}

All the 60 cases were followed up. The average follow up period was 5.5 months with the maximum being 12 months

\section{Conclusion}

The following conclusions were drawn from the study which was done in Hospital attached to Kamineni Institute of Medical Sciences. The study period was from January 2017 to July 2019.

1. The incidence of thyroid diseases is more common in females than in males.

2. The peak age group in which patients presented to the hospital was in $3^{\text {rd }}$ decade.

3. The commonest clinical diagnosis in patients with goitre was Multinodular Goitre in Euthyroid status.

4. The commonest histological diagnosis in those specimens sent for Histopathological examination was Nodular Colloid Goitre.

5. The most common surgery performed in goitre cases was Sub-total thyroidectomy.

6. Wound infection was the most common post-operative complication.

\section{Acknowledgment}

The author thankful to Department of Surgery for providing all the facilities to carry out this work.

\section{Conflict of Interest}

None

\section{References}

1. Lodovico Rosato, Nicola Avenia, Paolo Bernante, Maurizio De Palma, Giuseppe Gulino, Pier Giorgio Nasi et al. Complications of Thyroid Surgery: Analysis of a Multicentric Study on 14,934 Patients Operated on in Italy over 5 Years. World Journal of Surgery. 2004; 28:271-6.

2. Neil Bhattacharyya, Marvin P. Fried. Assessment of the Morbidity and Complications of Total Thyroidectomy. Arch Otolaryngol Head Neck Surg 2002; 128:389-92.

3. Bergenfelz A, Jansson S, Kristoffersson A, Martensson H, Reihner E, Wallin G et al. Complications to thyroid surgery: results as reported in a database from a multicenter audit comprising 3,660 patients. Langenbeck's Archives of Surgery. 2008; 393:667-73.

4. Nimet Suslu, Selahattin Vural, Mustafa Oncel, Burak Demirca, Cem Gezen F, Barıs Tuzun et al. Is the Insertion of Drains After Uncomplicated Thyroid Surgery Always Necessary?. Surgery Today 2006; 36:215-8.

5. Erbil Y, Barbaros U, Issever H, Borucu I, Salmaslioglu A, Mete $\mathrm{O}$ et al. Predictive factors for recurrent laryngeal nerve palsy and hypoparathyroidism after thyroid surgery. Clinical Otolaryngology. 2007; 32:32-7.

6. Hedley AJ, Bewsher PD, Jones SJ, Khir ASM, Clements P, Matheson NA et al. Late onset hypothyroidism after subtotal thyroidectomy for hyperthyroidism: Implications for long term follow-up. British Journal of Surgery. 1983; 70:740-3. 